\title{
A Process Study of the Tidal Circulation in the Persian Gulf
}

\author{
Stéphane Pous ${ }^{1}$, Xavier Carton ${ }^{2}$, Pascal Lazure ${ }^{3}$ \\ ${ }^{1}$ LOCEAN/IPSL, Université Pierre et Marie Curie, Paris, France \\ ${ }^{2}$ LPO/IUEM, Université de Bretagne Occidentale, Brest, France \\ ${ }^{3}$ DYNECO, IFREMER, Brest, France \\ Email: xcarton@univ-brest.fr
}

Received May 16, 2012; revised June 18, 2012; accepted July 3, 2012

\begin{abstract}
A homogeneous shallow-water model with free surface is used to model the tidal circulation in the Persian Gulf. The numerical finite-difference model includes harmonic diffusion of horizontal momentum and quadratic bottom friction, it has a $9 \mathrm{~km}$ mesh size and it is forced by 7 tidal components at its southern boundary. High precision bathymetric data are used to obtain the bottom topography. The numerical model is run for more than a year. The results are the following: 1) The model accurately reproduces the tidal phase and amplitude observed at 42 tidal gauges in the region. This accuracy is attributed to the presence of the 7 components which are able to interact nonlinearly; 2) The amphidromic points are also well positioned by the model due to a proper choice of bathymetry. This was checked also with a simpler geometry of the domain; 3) The tidal currents can be strong in the Straits of Hormuz and in shallow areas; thus they will have an effect of the hydrology of the region. The residual currents are weak so that they will be negligible for the large-scale circulation on long periods; 4) Finally, the sea-surface elevation forecast by the model is in close agreement with in-situ measurements of pressure in the Straits, performed during the GOGP99 experiment.
\end{abstract}

Keywords: Persian Gulf; Barotropic Tide; Hydrodynamical Modeling; Comparison with Data

\section{Introduction}

The Persian Gulf is a Northwest to Southeast oriented basin, with length of about $1000 \mathrm{~km}$, maximum width of $350 \mathrm{~km}$, average depth of $40 \mathrm{~m}$ and maximum depth of $120 \mathrm{~m}$ at the Straits of Hormuz; the straits open on the Gulf of Oman. The surface of the Persian Gulf is about $239,000 \mathrm{~km}^{2}$ and its volume is $8780 \mathrm{~km}^{3}$. It is bounded to the North by flat land (the delta of Iranian and Iraqi rivers), to the Northeast by the Zagros mountains, and to the Southwest by the desert of Saudi Arabia. High evaporation over the Persian Gulf leads to the formation of salty waters, called the Persian Gulf Water, which are exported into the Gulf of Oman, and which are compensated by an inflow of fresher Indian Ocean Surface Water. In the present study we will not consider the complex thermal and haline structure of the Persian Gulf, but we will study the tidal circulation in this gulf in a simple framework (assuming water mass homogeneity). Further work will address the circulation in a stratified case with thermal and haline and wind forcing.

The Persian Gulf has an oscillation period between 21.6 and 27 hours for tidal waves (from estimates by Defant [1]). In practice, semi-diurnal and diurnal waves generate resonant interactions in the basin which lead to a system of amphidromic points of Kelvin-Taylor type. In 1988, Bogdanov [2] constructed tidal charts with the M2, S2, K1 and O1 components, obtaining different results from those by Defant [1], especially concerning the position of amphidromic points of semi-diurnal waves. Several models [3-5], using independent wave components and prescribing the free surface at the boundary of the model domain, obtained an accurate position for the amphidromic points, but amplitudes and phases of the tide were not always well reproduced. Recently, the use of satellite data assimilation, reduced the model errors [6].

In this paper, we apply a 2D shallow water model over the Persian Gulf and the Northwestern Indian Ocean, forced by 7 tidal components at the southern boundary, and we describe the resulting tidal elevations and velocities; then we compare the model results with 42 tidal gauges recordings and with data from moorings of the GOGP99 experiment at sea, in the Straits of Hormuz.

\section{The Model}

A two-dimensional shallow-water model in spherical coordinates for a homogeneous ocean was implemented over a large domain comprising the Northwestern Indian 
Ocean, the Persian Gulf and the Gulf of Oman (see Figure 1(b)). The grid mesh was $9 \mathrm{~km}$ in each direction. Bathymetric data with a $5^{\prime} \times 5^{\prime}$ resolution were provided by Proctor for the Persian Gulf (see [7]) and elsewhere, ETOPO2 bathymetry was used (see Figure 1(a)). Four semidiurnal tidal components M2, S2, N2, K2 and three diurnal components K1, O1 and P1 were forced simultaneously on the water height at the southern boundary of this domain. This model was started from a state of rest and run over 375 days (the first 10 days being excluded from the analysis, because of dynamical adjustment of the model from the initial conditions). This long simulation allowed the nonlinear interactions between the seven tidal components to develop fully, and also allowed a correct separation of these components via harmonic analysis. This was a novel aspect of this study compared to former studies. A test was performed on the importance of the tidal generation potential: its inclusion in the model only led to very small differences from the results without it. Therefore the simulations presented below did not include this potential. The model had quadratic bottom friction proportional to gravity, to the modulus of velocity times its vector, and inversely proportional to the squared Strickler number (equal here to $45 \mathrm{~m}^{-1 / 3} \cdot \mathrm{s}^{-1}$ ) and to the cubic root of ocean depth (see also [8,9]) The model also had harmonic diffusion of horizontal mo-

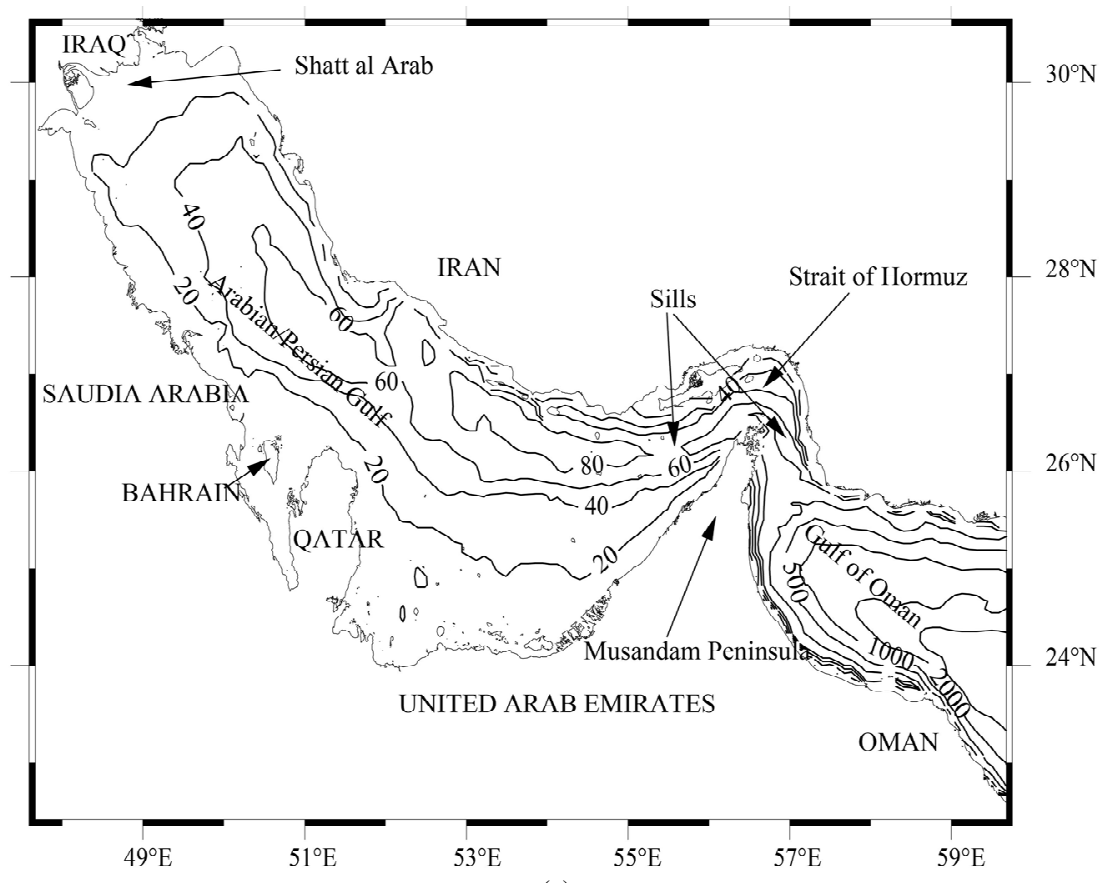

(a)

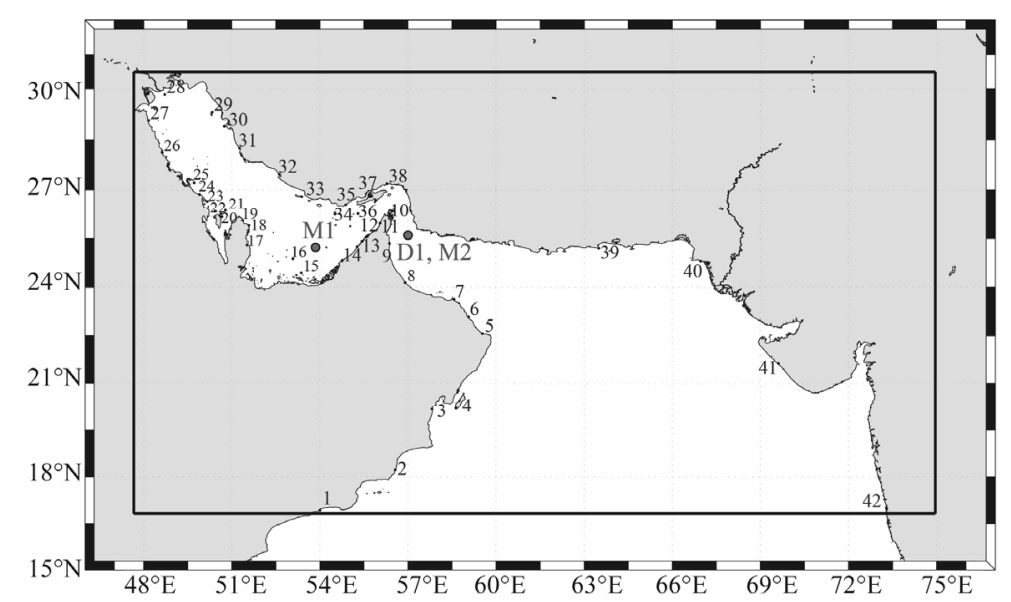

(b)

Figure 1. (a) Bathymetry and geography of the region of Persian Gulf and Gulf of Oman; (b) The small numbers indicate the location of tidal gauges used in tables 1 to 3 . Tide recorders M1 and M2 and ADCP mooring D1 sites are indicated by blue circles. The large black frame indicates the boundary of the 2D model domain. 
mentum with a diffusivity coefficient equal to $365 \mathrm{~m}^{2} \cdot \mathrm{s}^{-1}$.

\section{Tidal Circulation: Model Results and Validation}

Firstly we present the iso-amplitudes and iso-phases of tidal harmonics M2 and K1 in the Persian Gulf, provided by the model, in Figure 2. The two amphidromic points for semi-diurnal tides (east of Qatar and near $28^{\circ} 30^{\prime} \mathrm{N}$ and $50^{\circ} \mathrm{E}$ ), and the single amphidromic point off Qatar for diurnal tides are recovered. These results are in very good agreement with the analytical results by Defant [1] as well as with the assimilated solutions by Pontius [10].

For M2 and for K1, the model adequately reproduces the observed large amplitudes (on the order of 60 to 80 $\mathrm{cm}$ for M2 and $40 \mathrm{~cm}$ for $\mathrm{K} 1$ ) in the appropriate areas. For M2, these areas are the Straits of Hormuz, the region north of Qatar, and the southeastern part of the Gulf; for $\mathrm{K} 1$, these regions are the southeastern part of the Gulf and east of Qatar. For M2, the amplitudes between Qatar and Iran are in good agreement with observations while earlier studies tended to underestimate the amplitudes at this location. This good result can be attributed to the simultaneous use of 7 tidal components which can nonlinearly interact; indeed this constraint was absent from these earlier studies.

To validate the results, 42 time-series from tide gauges over the large domain were selected among the data at the International Hydrographic Office; these series were chosen under the condition that they be sufficiently long, continuous and consistent with neighboring tide gauges. Harmonic analysis was performed over the data and the model results and the 7 tidal components, presented in amplitude and phase, are listed in Tables $\mathbf{1}$ and 2. The model results are in very good agreement with the observations. The differences between the model and data are often smaller than 10 percent for the amplitude and 10 degrees for the phase. Components P1 and K2 are a little less accurate in direction because their amplitudes are weaker. This occurs also for a few cases of O1. It should be noted that the accuracy is good both in the Persian Gulf and in the Gulf of Oman. Therefore, the model adjusts everywhere from its distant forcing.

Table 3 provides an average value of the differences for the harmonic constants between model and data. This

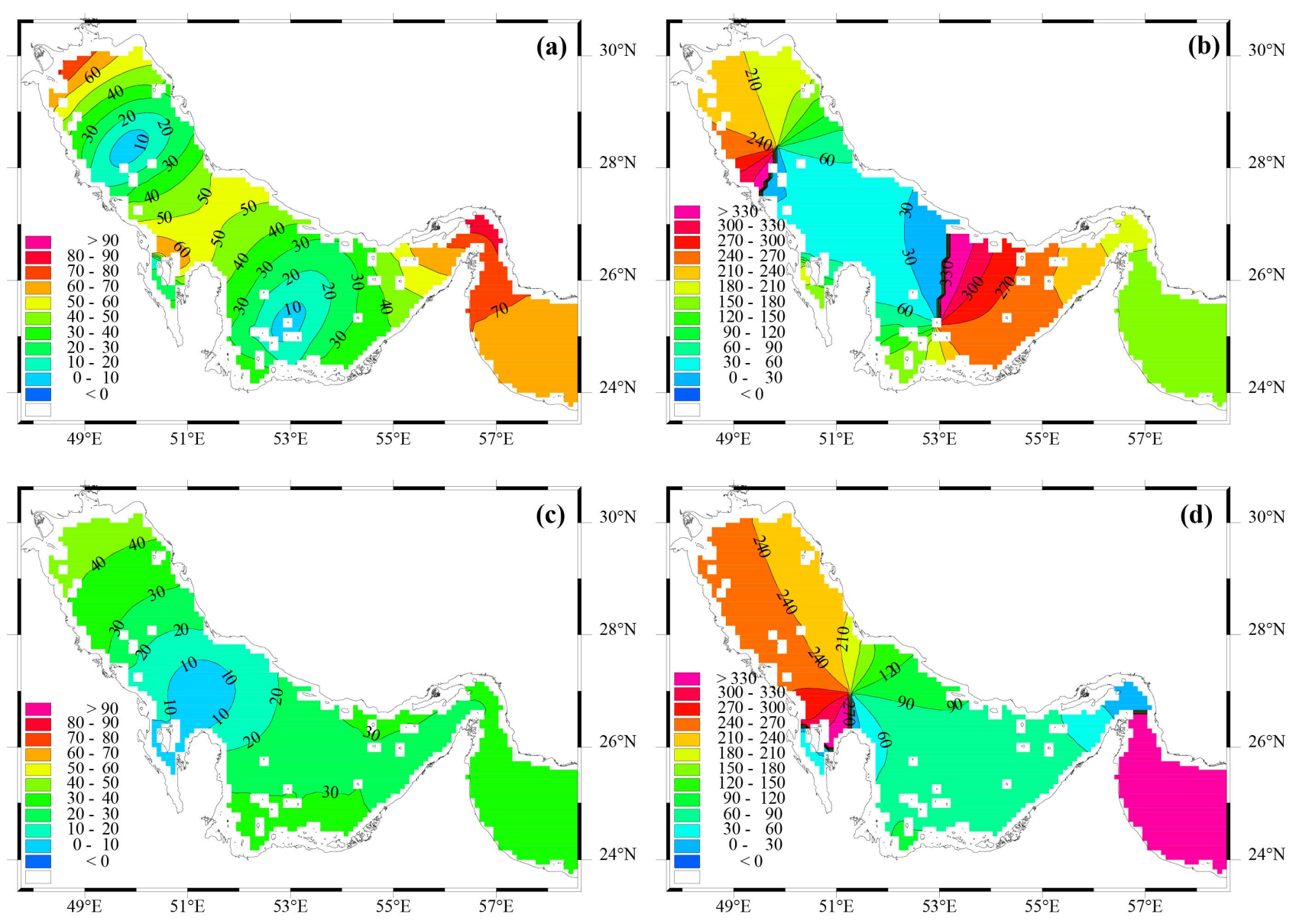

Figure 2. Iso-amplitude maps in $\mathrm{cm}$ (a), (c) and iso-phase maps in degree (b), (d) for tidal component M2 (resp. K1) in the Persian Gulf. 
Table 1. Comparison of the harmonic amplitudes in the model (mod.) and for observation (obs.) for the four main components $\mathrm{M} 2, \mathrm{~S} 2, \mathrm{~K} 1$ and $\mathrm{O1} . \mathrm{H}$ is the amplitude in $\mathrm{cm}, \mathrm{g}$ is the phase shift in degrees from Greenwich.

\begin{tabular}{|c|c|c|c|c|c|c|c|c|c|}
\hline & & \multicolumn{2}{|c|}{ M2 } & \multicolumn{2}{|c|}{ S2 } & \multicolumn{2}{|c|}{ K1 } & \multicolumn{2}{|c|}{ O1 } \\
\hline & & mod. & obs. & mod. & obs. & mod. & obs. & mod. & obs. \\
\hline Place & Position & $\mathrm{H} / \mathrm{g}$ & $\mathrm{H} / \mathrm{g}$ & $\mathrm{H} / \mathrm{g}$ & $\mathrm{H} / \mathrm{g}$ & $\mathrm{H} / \mathrm{g}$ & $\mathrm{H} / \mathrm{g}$ & $\mathrm{H} / \mathrm{g}$ & $\mathrm{H} / \mathrm{g}$ \\
\hline 1 Salalah & $16^{\circ} 56 / 54^{\circ} 00$ & $30 / 141$ & $31 / 145$ & $11 / 170$ & $12 / 168$ & $33 / 343$ & $36 / 345$ & $18 / 345$ & $18 / 348$ \\
\hline 2 Lakbi & $18^{\circ} 14 / 56^{\circ} 34$ & $39 / 153$ & $40 / 154$ & $14 / 183$ & $14 / 183$ & $34 / 343$ & $34 / 346$ & $18 / 345$ & $19 / 345$ \\
\hline 3 Sirab & $20^{\circ} 10 / 57^{\circ} 49$ & $47 / 158$ & $57 / 156$ & $17 / 189$ & $24 / 185$ & $35 / 341$ & $39 / 340$ & $18 / 345$ & $20 / 342$ \\
\hline 4 Rounders bay & $20^{\circ} 12 / 58^{\circ} 38$ & $46 / 158$ & $55 / 156$ & $17 / 188$ & 20/187 & $35 / 341$ & $42 / 346$ & $18 / 345$ & $19 / 343$ \\
\hline 5 Sur & $22^{\circ} 34 / 59^{\circ} 32$ & $61 / 162$ & $60 / 165$ & $22 / 193$ & 23/196 & $36 / 341$ & $40 / 351$ & $18 / 345$ & $19 / 342$ \\
\hline 6 Diba & $23^{\circ} 05 / 59^{\circ} 04$ & $62 / 162$ & $62 / 160$ & 23/193 & $26 / 194$ & $37 / 341$ & 33/339 & $18 / 345$ & $22 / 344$ \\
\hline 7 Muscat & $23^{\circ} 38 / 58^{\circ} 34$ & $64 / 163$ & $63 / 160$ & 23/194 & 24/191 & $37 / 341$ & $39 / 342$ & $18 / 345$ & $20 / 343$ \\
\hline 8 Saham & $24^{\circ} 09 / 56^{\circ} 54$ & $69 / 163$ & $68 / 159$ & $25 / 194$ & $26 / 189$ & $37 / 341$ & $40 / 339$ & $18 / 345$ & $22 / 343$ \\
\hline 9 Khor al Fakkan & $25^{\circ} 21 / 56^{\circ} 22$ & $71 / 165$ & $66 / 162$ & 26/196 & 27/192 & $37 / 341$ & $35 / 340$ & $18 / 346$ & $19 / 346$ \\
\hline 10 Ras Dillah & $26^{\circ} 08 / 56^{\circ} 28$ & $74 / 171$ & $72 / 174$ & $27 / 202$ & $27 / 202$ & $34 / 345$ & $31 / 341$ & $18 / 349$ & $19 / 353$ \\
\hline 11 Khor Khwair & $25^{\circ} 58 / 56^{\circ} 03$ & $61 / 220$ & $62 / 210$ & $20 / 262$ & $20 / 250$ & $23 / 53$ & $21 / 29$ & $15 / 23$ & $16 / 28$ \\
\hline 12 Ajman & $25^{\circ} 25 / 55^{\circ} 26$ & $47 / 238$ & $43 / 248$ & $17 / 284$ & $13 / 301$ & $25 / 73$ & $17 / 103$ & $14 / 33$ & $15 / 50$ \\
\hline 13 Dubai & $25^{\circ} 15 / 55^{\circ} 16$ & $42 / 247$ & $44 / 237$ & $16 / 297$ & $16 / 281$ & $27 / 80$ & 23/91 & $14 / 37$ & $16 / 42$ \\
\hline 14 Khor Ghanada & $24^{\circ} 50 / 54^{\circ} 46$ & $38 / 254$ & $42 / 263$ & $15 / 305$ & $15 / 318$ & $29 / 83$ & $27 / 105$ & $13 / 39$ & $15 / 56$ \\
\hline 15 H. al Mubarras & $24^{\circ} 27 / 53^{\circ} 22$ & $32 / 251$ & $28 / 261$ & $14 / 310$ & $13 / 315$ & $33 / 83$ & $43 / 102$ & $14 / 38$ & $23 / 52$ \\
\hline 16 Zarqa & $24^{\circ} 53 / 53^{\circ} 05$ & $11 / 212$ & $11 / 266$ & $5 / 313$ & $4 / 337$ & $32 / 83$ & $36 / 95$ & $13 / 37$ & $16 / 62$ \\
\hline 17 Ad Dawhah & $25^{\circ} 18 / 51^{\circ} 31$ & $36 / 67$ & $32 / 51$ & 9/109 & $11 / 82$ & $27 / 59$ & $36 / 72$ & $10 / 12$ & $16 / 28$ \\
\hline 18 Ras Laffan & $25^{\circ} 54 / 51^{\circ} 35$ & $44 / 46$ & $38 / 37$ & $13 / 103$ & $11 / 76$ & $16 / 44$ & $25 / 53$ & $5 / 353$ & $12 / 0$ \\
\hline 19 Jabal Fuwairat & $26^{\circ} 03 / 51^{\circ} 22$ & $49 / 46$ & $42 / 44$ & $15 / 106$ & $13 / 88$ & $12 / 33$ & $20 / 54$ & $4 / 333$ & $9 / 0$ \\
\hline 20 Sitra & $26^{\circ} 10 / 50^{\circ} 40$ & $58 / 73$ & $66 / 58$ & $21 / 137$ & $19 / 120$ & $8 / 342$ & $10 / 347$ & $5 / 275$ & $6 / 264$ \\
\hline 21 Bharain & $26^{\circ} 22 / 50^{\circ} 47$ & $63 / 57$ & $63 / 54$ & $22 / 119$ & $20 / 102$ & 9/326 & $9 / 10$ & $5 / 262$ & $7 / 268$ \\
\hline 22 Khwar Fasht & $26^{\circ} 20 / 50^{\circ} 26$ & $66 / 50$ & $55 / 62$ & $24 / 113$ & $20 / 114$ & $12 / 293$ & 8/343 & $7 / 241$ & $8 / 256$ \\
\hline 23 Ras Tannurah & $26^{\circ} 39 / 50^{\circ} 10$ & $57 / 38$ & $60 / 42$ & $21 / 100$ & $20 / 98$ & $14 / 277$ & $14 / 294$ & $9 / 229$ & $12 / 238$ \\
\hline 24 Ras al Qulay’ah & $26^{\circ} 52 / 49^{\circ} 54$ & $51 / 35$ & $48 / 36$ & $19 / 98$ & $16 / 93$ & $16 / 269$ & $18 / 274$ & $9 / 223$ & $10 / 218$ \\
\hline 25 Berri & $27^{\circ} 13 / 49^{\circ} 43$ & $43 / 33$ & $44 / 37$ & $17 / 98$ & $16 / 107$ & $18 / 262$ & $17 / 273$ & $10 / 219$ & $14 / 227$ \\
\hline 26 Ras al Mishaab & $28^{\circ} 07 / 48^{\circ} 38$ & $32 / 262$ & $25 / 276$ & $10 / 326$ & 8/335 & $38 / 256$ & $38 / 259$ & $19 / 214$ & $21 / 221$ \\
\hline 27 Mina al Ahmadi & $29^{\circ} 04 / 48^{\circ} 10$ & $64 / 237$ & $63 / 248$ & $22 / 299$ & $17 / 312$ & $44 / 252$ & $43 / 263$ & $21 / 211$ & $29 / 215$ \\
\hline 28 Shatt al Arab & $29^{\circ} 50 / 48^{\circ} 43$ & $74 / 217$ & $84 / 221$ & $26 / 279$ & $29 / 279$ & $46 / 244$ & $50 / 250$ & $22 / 203$ & $30 / 205$ \\
\hline 29 Jazh ye Khark & $29^{\circ} 19 / 50^{\circ} 20$ & $30 / 169$ & $36 / 149$ & $10 / 223$ & $13 / 196$ & $36 / 230$ & $39 / 233$ & $18 / 190$ & $26 / 192$ \\
\hline 30 Bushehr & $28^{\circ} 54 / 50^{\circ} 45$ & $24 / 120$ & $34 / 110$ & $9 / 172$ & $12 / 160$ & $31 / 223$ & $31 / 227$ & $16 / 184$ & 20/189 \\
\hline 31 Lavar & $28^{\circ} 15 / 51^{\circ} 16$ & $38 / 63$ & $50 / 68$ & $15 / 120$ & $18 / 117$ & $21 / 207$ & $25 / 209$ & $12 / 171$ & $18 / 171$ \\
\hline 32 Asalu & $27^{\circ} 28 / 52^{\circ} 37$ & $52 / 28$ & $51 / 19$ & $17 / 83$ & $17 / 57$ & $18 / 117$ & $24 / 115$ & $8 / 90$ & $12 / 89$ \\
\hline 33 Jezirat Lavan & $26^{\circ} 48 / 53^{\circ} 23$ & $33 / 350$ & $30 / 335$ & $10 / 34$ & $12 / 10$ & $27 / 91$ & $29 / 94$ & $11 / 58$ & $15 / 55$ \\
\hline 34 Jezirat Forur & $26^{\circ} 15 / 54^{\circ} 31$ & $35 / 273$ & $45 / 259$ & $13 / 316$ & $15 / 295$ & $30 / 78$ & $38 / 86$ & $14 / 43$ & $22 / 42$ \\
\hline 35 Bandar Lengeh & $26^{\circ} 44 / 54^{\circ} 53$ & $55 / 249$ & $60 / 230$ & $19 / 292$ & $23 / 267$ & $32 / 68$ & $33 / 67$ & $16 / 36$ & $22 / 33$ \\
\hline 36 Jezirat Tunbh & $26^{\circ} 16 / 55^{\circ} 18$ & $55 / 239$ & $59 / 232$ & $19 / 283$ & $20 / 269$ & $30 / 65$ & $29 / 66$ & $16 / 33$ & $19 / 39$ \\
\hline 37 Henjam & $26^{\circ} 41 / 55^{\circ} 54$ & $70 / 221$ & $74 / 204$ & $24 / 261$ & $25 / 247$ & $30 / 46$ & $29 / 28$ & $18 / 22$ & $20 / 14$ \\
\hline 38 Bandar Abbas & $27^{\circ} 11 / 56^{\circ} 17$ & $95 / 196$ & 00/197 & $33 / 231$ & $36 / 229$ & $34 / 15$ & $34 / 11$ & $20 / 6$ & $21 / 3$ \\
\hline 39 Pasni & $25^{\circ} 12 / 63^{\circ} 30$ & $61 / 160$ & $72 / 166$ & $22 / 191$ & 26/192 & $37 / 339$ & 28/335 & $18 / 344$ & $21 / 346$ \\
\hline 40 Karachi & $24^{\circ} 48 / 66^{\circ} 58$ & $70 / 161$ & $79 / 163$ & 26/192 & $30 / 194$ & 38/339 & $40 / 341$ & $18 / 343$ & $20 / 342$ \\
\hline 41 Porbandar & $21^{\circ} 38 / 69^{\circ} 37$ & $61 / 161$ & $65 / 180$ & $22 / 192$ & $24 / 211$ & $36 / 337$ & $35 / 347$ & $17 / 342$ & $17 / 350$ \\
\hline 42 Ratnagiri & $16^{\circ} 59 / 73^{\circ} 18$ & $61 / 170$ & $66 / 175$ & $21 / 203$ & $26 / 209$ & $34 / 335$ & $35 / 340$ & $16 / 343$ & $16 / 349$ \\
\hline M1 & $25^{\circ} 14 / 53^{\circ} 51$ & $25 / 267$ & $31 / 262$ & $11 / 316$ & $13 / 296$ & 29/81 & $34 / 90$ & $13 / 39$ & $20 / 43$ \\
\hline M2 & $25^{\circ} 36 / 57^{\circ} 00$ & $72 / 165$ & $70 / 161$ & 26/196 & 29/190 & $37 / 343$ & 47/335 & $19 / 346$ & $21 / 347$ \\
\hline
\end{tabular}


Table 2. Comparison of the harmonic amplitudes in the model (mod.) and for observation (obs.) for the other waves N2, K2 and $\mathrm{P1} . \mathrm{H}$ is the amplitude in $\mathrm{cm}$, $\mathrm{g}$ is the phase shift in degrees from Greenwich. The last column shows $\mathrm{F}$, the type of tide.

\begin{tabular}{|c|c|c|c|c|c|c|c|c|c|}
\hline & & \multicolumn{2}{|c|}{ N2 } & \multicolumn{2}{|c|}{ K2 } & \multicolumn{2}{|c|}{ P1 } & \multicolumn{2}{|c|}{ Type F } \\
\hline & & mod. & obs. & mod. & obs. & mod. & obs. & mod. & obs. \\
\hline Place & Position & $\mathrm{H} / \mathrm{g}$ & $\mathrm{H} / \mathrm{g}$ & $\mathrm{H} / \mathrm{g}$ & $\mathrm{H} / \mathrm{g}$ & $\mathrm{H} / \mathrm{g}$ & $\mathrm{H} / \mathrm{g}$ & Fc. & Fo. \\
\hline 1 Salalah & $16^{\circ} 56 / 54^{\circ} 00$ & 8/137 & $8 / 133$ & $3 / 168$ & $3 / 161$ & $11 / 343$ & $11 / 343$ & 1.23 & 1.26 \\
\hline 2 Lakbi & $18^{\circ} 14 / 56^{\circ} 34$ & $10 / 146$ & $11 / 138$ & $4 / 182$ & $4 / 183$ & $11 / 343$ & $12 / 347$ & 0.99 & 0.98 \\
\hline 3 Sirab & $20^{\circ} 10 / 57^{\circ} 49$ & $11 / 149$ & $14 / 138$ & $5 / 188$ & $6 / 185$ & $12 / 342$ & $13 / 340$ & 0.82 & 0.73 \\
\hline 4 Rounders bay & $20^{\circ} 12 / 58^{\circ} 38$ & $11 / 148$ & $14 / 140$ & $5 / 187$ & 6/187 & $12 / 341$ & $14 / 346$ & 0.84 & 0.81 \\
\hline 5 Sur & $22^{\circ} 34 / 59^{\circ} 32$ & $14 / 151$ & $15 / 146$ & $6 / 193$ & 6/195 & $12 / 341$ & $13 / 351$ & 0.66 & 0.71 \\
\hline 6 Diba & $23^{\circ} 05 / 59^{\circ} 04$ & $14 / 152$ & $16 / 147$ & 6/192 & $7 / 194$ & $12 / 341$ & $11 / 339$ & 0.65 & 0.63 \\
\hline 7 Muscat & $23^{\circ} 38 / 58^{\circ} 34$ & $15 / 152$ & $16 / 141$ & 7/192 & $6 / 184$ & $12 / 341$ & $12 / 340$ & 0.63 & 0.69 \\
\hline 8 Saham & $24^{\circ} 09 / 56^{\circ} 54$ & $16 / 152$ & $17 / 139$ & 7/193 & 7/188 & $12 / 342$ & $13 / 339$ & 0.59 & 0.65 \\
\hline 9 Khor al Fakkan & $25^{\circ} 21 / 56^{\circ} 22$ & $17 / 154$ & $13 / 155$ & 7/195 & 7/192 & $12 / 342$ & $12 / 340$ & 0.57 & 0.58 \\
\hline 10 Ras Dillah & $26^{\circ} 08 / 56^{\circ} 28$ & $17 / 159$ & $18 / 160$ & $8 / 201$ & $7 / 202$ & $11 / 345$ & $11 / 341$ & 0.52 & 0.51 \\
\hline 11 Khor Khwair & $25^{\circ} 58 / 56^{\circ} 03$ & $14 / 204$ & $11 / 212$ & $6 / 258$ & $5 / 250$ & $7 / 48$ & $7 / 29$ & 0.47 & 0.45 \\
\hline 12 Ajman & $25^{\circ} 25 / 55^{\circ} 26$ & $11 / 220$ & $1 / 227$ & $5 / 281$ & $4 / 301$ & $8 / 69$ & $6 / 103$ & 0.61 & 0.57 \\
\hline 13 Dubai & $25^{\circ} 15 / 55^{\circ} 16$ & 9/229 & $10 / 217$ & $5 / 293$ & $5 / 265$ & $8 / 77$ & 7/77 & 0.71 & 0.64 \\
\hline 14 Khor Ghanada & $24^{\circ} 50 / 54^{\circ} 46$ & $8 / 235$ & $9 / 248$ & $5 / 300$ & $4 / 318$ & $9 / 80$ & 9/105 & 0.79 & 0.74 \\
\hline 15 H. al Mubarras & $24^{\circ} 27 / 53^{\circ} 22$ & $6 / 232$ & $4 / 232$ & $5 / 300$ & 3/315 & $9 / 82$ & $14 / 102$ & 1.00 & 1.62 \\
\hline 16 Zarqa & $24^{\circ} 53 / 53^{\circ} 05$ & $2 / 164$ & $1 / 227$ & $2 / 292$ & $1 / 343$ & $9 / 83$ & $12 / 93$ & 2.90 & 3.43 \\
\hline 17 Ad Dawhah & $25^{\circ} 18 / 51^{\circ} 31$ & $9 / 44$ & $9 / 30$ & $3 / 128$ & $3 / 70$ & $8 / 59$ & $10 / 67$ & 0.80 & 1.23 \\
\hline 18 Ras Laffan & $25^{\circ} 54 / 51^{\circ} 35$ & $10 / 22$ & $10 / 12$ & $5 / 103$ & $3 / 64$ & $5 / 44$ & $7 / 48$ & 0.37 & 0.76 \\
\hline 19 Jabal Fuwairat & $26^{\circ} 03 / 51^{\circ} 22$ & $11 / 22$ & $11 / 17$ & $6 / 101$ & $4 / 88$ & $3 / 33$ & $7 / 54$ & 0.25 & 0.53 \\
\hline 20 Sitra & $26^{\circ} 10 / 50^{\circ} 40$ & $12 / 48$ & $13 / 29$ & $8 / 125$ & $5 / 120$ & $2 / 334$ & $3 / 347$ & 0.16 & 0.19 \\
\hline 21 Bharain & $26^{\circ} 22 / 50^{\circ} 47$ & $13 / 31$ & $12 / 20$ & 9/108 & $5 / 102$ & 2/319 & $3 / 10$ & 0.16 & 0.19 \\
\hline 22 Khwar Fasht & $26^{\circ} 20 / 50^{\circ} 26$ & $13 / 25$ & $10 / 36$ & 9/102 & $5 / 114$ & $3 / 285$ & $3 / 343$ & 0.21 & 0.21 \\
\hline 23 Ras Tannurah & $26^{\circ} 39 / 50^{\circ} 10$ & $11 / 13$ & $13 / 13$ & $8 / 90$ & $7 / 77$ & $4 / 270$ & $4 / 274$ & 0.29 & 0.33 \\
\hline 24 Ras al Qulay’ah & $26^{\circ} 52 / 49^{\circ} 54$ & $10 / 11$ & $10 / 9$ & $7 / 87$ & $4 / 93$ & $5 / 263$ & $6 / 274$ & 0.36 & 0.44 \\
\hline 25 Berri & $27^{\circ} 13 / 49^{\circ} 43$ & $8 / 11$ & $9 / 5$ & $6 / 86$ & $4 / 107$ & $5 / 257$ & $6 / 273$ & 0.47 & 0.52 \\
\hline 26 Ras al Mishaab & $28^{\circ} 07 / 48^{\circ} 38$ & $7 / 234$ & $6 / 243$ & $4 / 319$ & $3 / 334$ & $11 / 253$ & $13 / 253$ & 1.35 & 1.79 \\
\hline 27 Mina al Ahmadi & $29^{\circ} 04 / 48^{\circ} 10$ & $13 / 213$ & $12 / 226$ & 9/292 & $5 / 312$ & $13 / 249$ & $14 / 263$ & 0.76 & 0.90 \\
\hline 28 Shatt al Arab & $29^{\circ} 50 / 48^{\circ} 43$ & $15 / 195$ & $17 / 189$ & $10 / 272$ & $10 / 260$ & $14 / 242$ & $14 / 243$ & 0.68 & 0.71 \\
\hline 29 Jazh ye Khark & $29^{\circ} 19 / 50^{\circ} 20$ & $7 / 147$ & $8 / 134$ & $4 / 219$ & $4 / 190$ & $11 / 227$ & $12 / 222$ & 1.34 & 1.31 \\
\hline 30 Bushehr & $28^{\circ} 54 / 50^{\circ} 45$ & $5 / 100$ & $7 / 84$ & $3 / 165$ & $4 / 156$ & $9 / 220$ & $9 / 218$ & 1.43 & 1.11 \\
\hline 31 Lavar & $28^{\circ} 15 / 51^{\circ} 16$ & $8 / 41$ & $40 / 44$ & $5 / 111$ & $5 / 117$ & $7 / 203$ & $9 / 210$ & 0.62 & 0.64 \\
\hline 32 Asalu & $27^{\circ} 28 / 52^{\circ} 37$ & $11 / 6$ & $11 / 352$ & $6 / 79$ & $5 / 57$ & $6 / 115$ & $8 / 116$ & 0.38 & 0.52 \\
\hline 33 Jezirat Lavan & $26^{\circ} 48 / 53^{\circ} 23$ & $7 / 330$ & $8 / 321$ & $3 / 37$ & $4 / 300$ & $8 / 90$ & $10 / 328$ & 0.89 & 1.05 \\
\hline 34 Jezirat Forur & $26^{\circ} 15 / 54^{\circ} 31$ & $8 / 257$ & $9 / 253$ & $4 / 313$ & $4 / 295$ & $9 / 76$ & $13 / 86$ & 0.94 & 0.99 \\
\hline 35 Bandar Lengeh & $26^{\circ} 44 / 54^{\circ} 53$ & $12 / 232$ & $13 / 212$ & $6 / 289$ & $1 / 265$ & $10 / 64$ & $11 / 62$ & 0.65 & 0.66 \\
\hline 36 Jezirat Tunbh & $26^{\circ} 16 / 55^{\circ} 18$ & $12 / 223$ & $14 / 208$ & $6 / 280$ & $6 / 269$ & $9 / 61$ & $10 / 66$ & 0.62 & 0.61 \\
\hline 37 Henjam & $26^{\circ} 41 / 55^{\circ} 54$ & $16 / 206$ & $17 / 178$ & $7 / 259$ & $7 / 247$ & $10 / 42$ & $9 / 28$ & 0.51 & 0.50 \\
\hline 38 Bandar Abbas & $27^{\circ} 11 / 56^{\circ} 17$ & $22 / 183$ & $22 / 180$ & $10 / 229$ & $10 / 227$ & $11 / 13$ & $11 / 10$ & 0.42 & 0.40 \\
\hline 39 Pasni & $25^{\circ} 12 / 63^{\circ} 30$ & $14 / 149$ & $17 / 174$ & $6 / 190$ & $7 / 192$ & $12 / 340$ & 9/336 & 0.66 & 0.50 \\
\hline 40 Karachi & $24^{\circ} 48 / 66^{\circ} 58$ & $16 / 150$ & $18 / 147$ & $7 / 191$ & 8/185 & $12 / 340$ & $11 / 337$ & 0.58 & 0.56 \\
\hline 41 Porbandar & $21^{\circ} 38 / 69^{\circ} 37$ & $14 / 148$ & $16 / 163$ & 6/191 & $7 / 214$ & $12 / 337$ & $10 / 347$ & 0.64 & 0.59 \\
\hline 42 Ratnagiri & $16^{\circ} 59 / 73^{\circ} 18$ & $13 / 155$ & $15 / 158$ & $6 / 203$ & $7 / 212$ & $11 / 335$ & $11 / 341$ & 0.61 & 0.55 \\
\hline M1 & $25^{\circ} 14 / 53^{\circ} 51$ & $5 / 252$ & $6 / 243$ & 3/307 & $4 / 300$ & $9 / 79$ & $11 / 86$ & 1.18 & 1.20 \\
\hline M2 & $25^{\circ} 36 / 57^{\circ} 00$ & $17 / 153$ & $17 / 145$ & 7/195 & 8/192 & $12 / 343$ & $15 / 308$ & 0.57 & 0.68 \\
\hline
\end{tabular}


Table 3. Mean value of the differences between the model and the observed harmonic amplitudes $\mathbf{H}$ (in $\mathbf{c m}$ ) and phase $\mathrm{g}$ (in degrees).

\begin{tabular}{lccccccc}
\hline \multirow{2}{*}{ Averaged difference for the: } & M2 & S2 & K1 & O1 & N2 & K2 & P1 \\
\cline { 2 - 8 } & H/g & H/g & H/g & H/g & H/g & H/g & H/g \\
\hline 11 gauges of Arabian Sea & $4 / 5$ & $2 / 4$ & $3 / 4$ & $2 / 3$ & $1 / 9$ & $0 / 6$ & $1 / 4$ \\
31 gauges of the Persian Gulf & $5 / 10$ & $2 / 13$ & $3 / 11$ & $4 / 8$ & $3 / 11$ & $1 / 19$ & $1 / 19$ \\
42 gauges (total) & $5 / 9$ & $2 / 11$ & $3 / 10$ & $3 / 6$ & $2 / 11$ & $1 / 14$ & $1 / 10$ \\
\hline
\end{tabular}

average is taken over all tidal gauges in the gulf, in the Arabian Sea or in the whole domain. Again, the model results agree very well with the observations. The averaged differences are on the order of a few centimeters for the amplitude and a few degrees for the phase. Very small errors are found in the Arabian Sea. The largest errors are found for waves K2 and P1 in the Persian Gulf; these errors can come from both the model and the measurements.

Another element of the model which leads to precise results is the accurate bathymetry in the Persian Gulf (see also [11]). Navigation charts had originally been used to provide the bottom depth in the gulf; but these charts were not accurate enough (the gulf was too shallow) and they led to a misrepresentation of the amphidromic points. This was corrected by using the bathymetry provided by Proctor and complemented with ETOPO2. The difference between the depth of the navigation charts and that used finally in the model was about $10 \mathrm{~m}$ on average over the gulf.

To show how important an accurate bathymetry is for the model, we tested the influence of bottom topography on tides in the idealized case of a rectangular basin with an open strait at its eastern boundary; in that case, the tide was prescribed at this strait with the same amplitude and phase as in the real Persian Gulf.

Indeed, Defant [1] considered the reflection of Kelvin waves in a semi-enclosed rectangular basin, and showed that the natural period of waves in a basin comparable to the Persian Gulf was 22 - 23 hours. Thus, with a diurnal or semi-diurnal forcing, resonance oscillations can appear. When the forcing is a semi-diurnal wave, two amphidromic points should appear.

These two points are recovered in our simple basin experiment when the average depth is $40 \mathrm{~m}$ but not when it is $30 \mathrm{~m}$. This shows that a proper bathymetry is critical for a good representation of tides.

Finally, the nature of the tide in the Gulf varies depending on the location. Table 2 provide the value of ratio $\mathrm{F}$ defined as $\mathrm{F}=(\mathrm{K} 1+\mathrm{O} 1) /(\mathrm{M} 2+\mathrm{S} 2)$, which characterizes the type (diurnal, semi-diurnal or mixed) of tide. For $\mathrm{F}<0.25$ the tide is semi-diurnal; for $0.25<\mathrm{F}<1.5$, the tide is semi-diurnal with diurnal inequality; for $1.5<$ $\mathrm{F}<3.0$, the tide is mixed; and finally, for $\mathrm{F}>3.0$, the tide is diurnal. Figure 3 shows the value of factor $F$ in the Persian Gulf. The model correctly reproduces the three types of tides (semi-diurnal, mixed and diurnal) observed by John [12]. Figure 4 shows the time evolution of the free surface in the 2D model at three points with different types of tides. Point $\mathrm{A}$ is located near the diurnal amphidromic point; since the diurnal component of the free surface elevation is zero at the amphidromic point, the semi-diurnal component dominates the tidal signal as observed. Conversely, point B is located near the semi-diurnal amphidromic point so that the diurnal component dominates. Finally, point $\mathrm{C}$ is not close to an amphidromic point so that the tide is mixed at this point as shown by Figure 4.

Figure 5(a) shows the maximal velocities of the tidal current in the Persian Gulf over the year of simulation; these current maxima do not necessarily occur at the same time everywhere. Tidal currents can be fast nearly everywhere in the Gulf; a striking feature is that such fast currents do not specifically depend on the type of tide. In particular, currents faster than $1 \mathrm{~m} / \mathrm{s}$ are found in the Straits of Hormuz and around islands. Eulerian residual currents were then computed (because the mesh size is too large to allow the computation of Lagrangian residual currents) at a time of maximal diurnal and semi-diurnal currents; this period was near day 165 of the simulation. The currents were then averaged over a 20 day period around that date (to filter the instantaneous tidal signal). The residual currents are weak over the whole Gulf; velocities do not exceed 2 cm/s (see Figure 5(b)). An anticyclonic current pattern can be seen north of Qatar with an intensification along the Iranian coast. Faster recirculations are observed along the coasts, around islands and in the Straits of Hormuz. These results agree with those of a finite element model by [13].

\section{Validation with Complementary Data}

A complementary validation was performed using data from the GOGP99 experiment at sea (see [14,15]). This experiment was carried out in the Straits of Hormuz and in the Gulf of Oman in October 1999. Figure 1(b) shows the location of the moorings M1, M2 and D1 of this experiment.

D1 is a Doppler current-meter; it was moored at $120 \mathrm{~m}$ depth at the exit of the Straits of Hormuz. The Doppler 


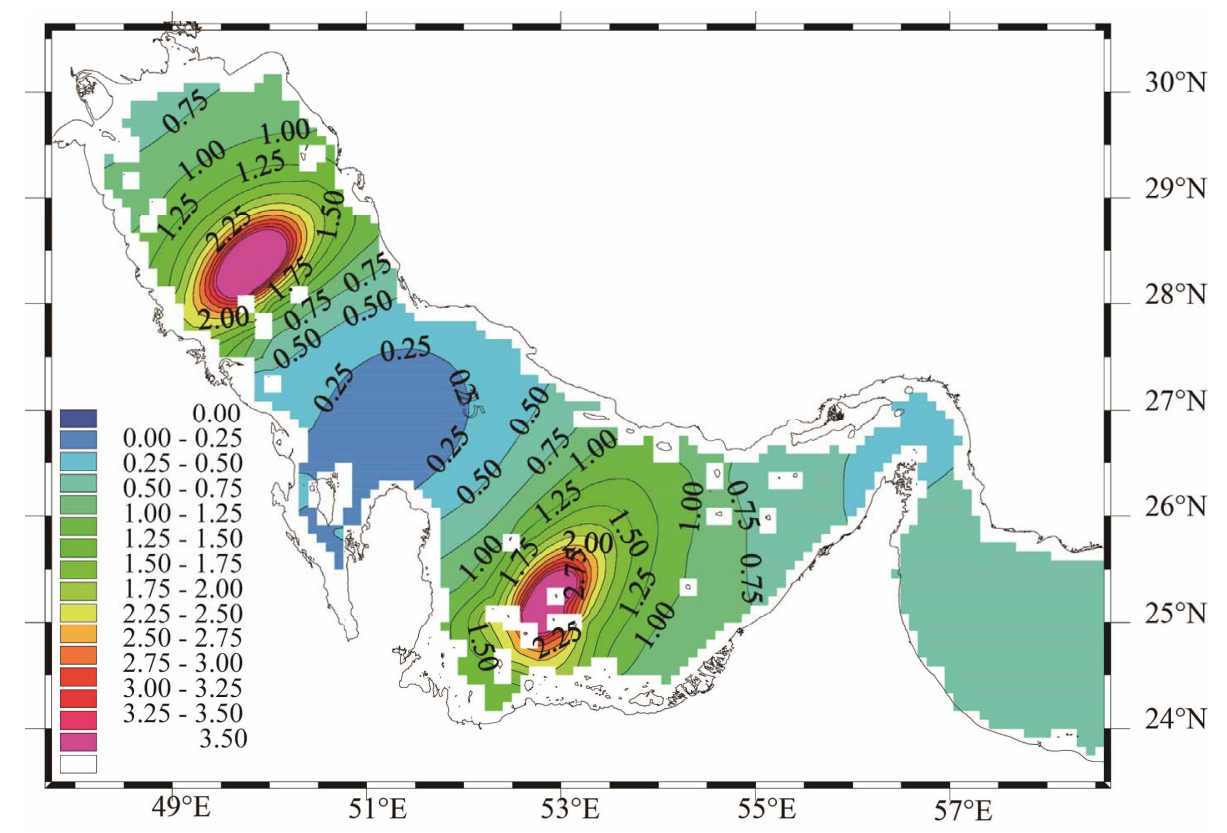

Figure 3. Map of factor $F$ over the Persian Gulf indicating the type of tide.

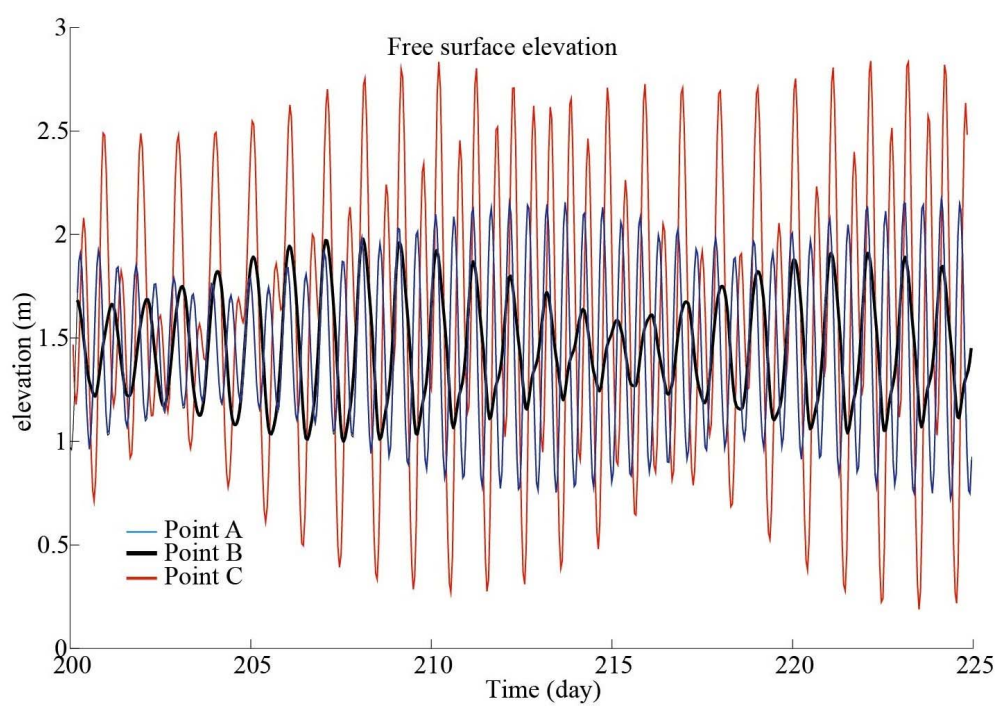

Figure 4. Time evolution of the free surface deviation (in meters) in the model for three areas typical of the Persian Gulf. Point $A$ is located near the diurnal amphidromic point, point $B$ is located near the westernmost semi-diurnal amphidromic point and point $C$ lies in the northwesternmost part of the Gulf, near the Shatt-al-Arab.

current-meter was equipped with a pressure probe and recorder which provided a time-series. In Figure 6, this pressure measurement is compared with the variation of the free surface elevation simulated by the model, once the average has been substracted from each series of data, during the same period. The two curves are strikingly similar both in amplitude (where the difference is a few centimeters only) and in phase. We can assume that the effects of the meteorological forcings at the ocean surface have been approximately canceled by substracting the 10-day average.
Furthermore, two tide gauges, M1 and M2, have been moored at the entrance and exit of the Straits of Hormuz, for about a month in 1999. After the experiment, a harmonic analysis of the data was achieved and the amplitude and phase of the main components of the tide were determined at each point. These results were then compared with those forecast at the same points by the numerical model. It is interesting to note that these measurements lie in the open sea, contrary to those which were used above to validate the model. The agreement between model and data is good with a difference of only 


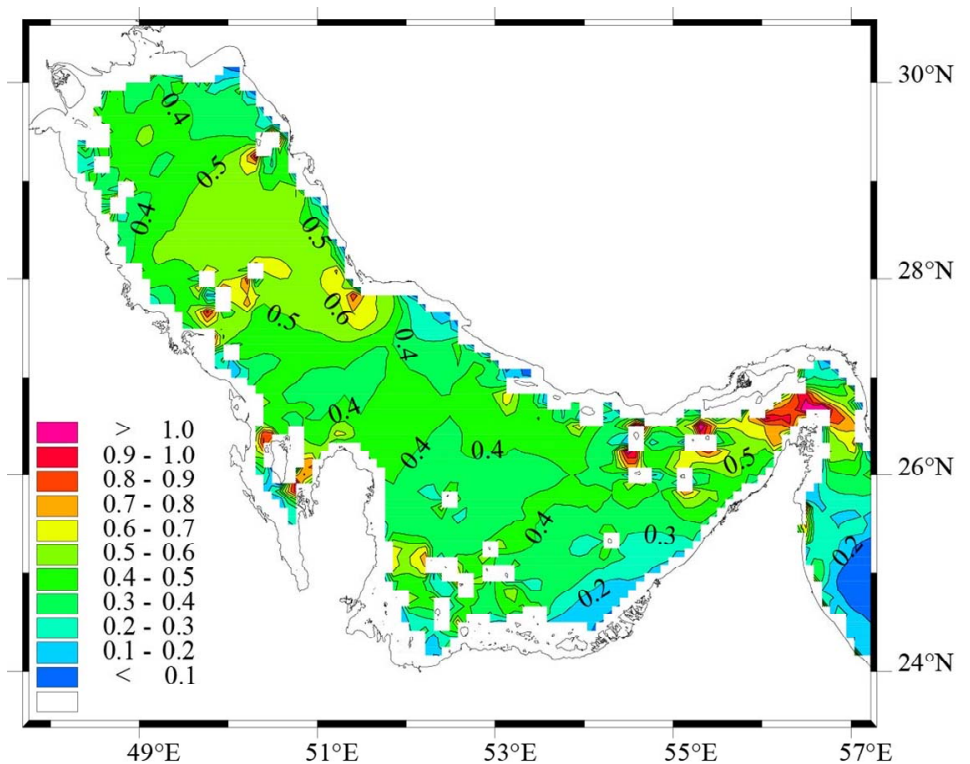

(a)

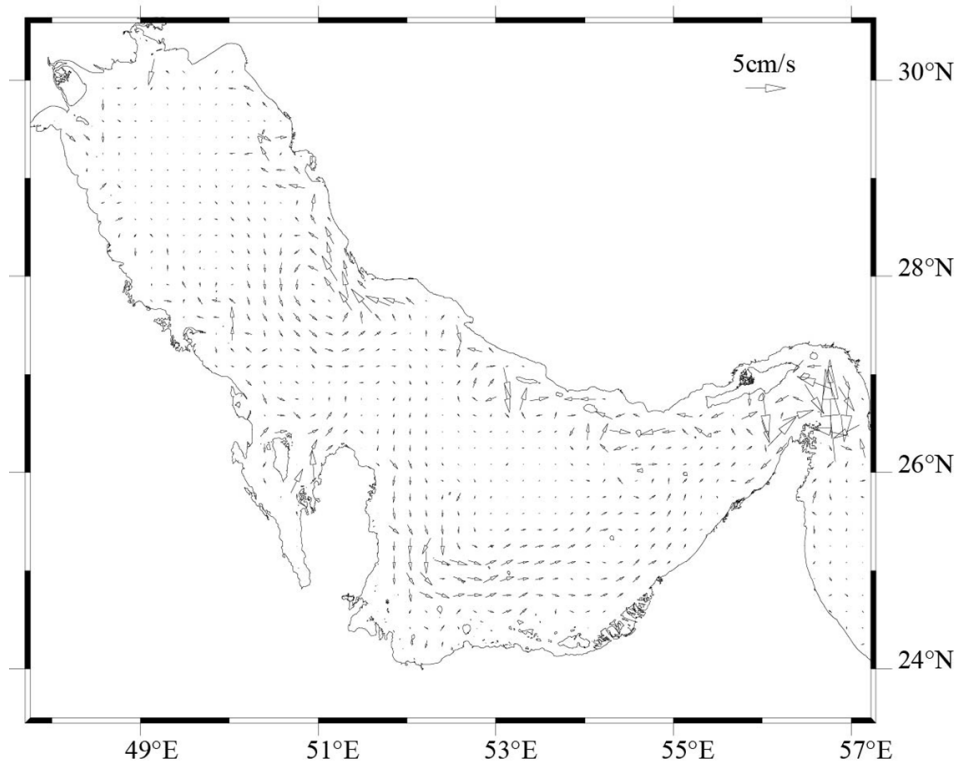

(b)

Figure 5. (a) Maximum velocities of tidal currents in the persian gulf (in m/s); (b) Residual tidal current in the persian gulf.

a few centimeters for all waves between the modeled and measured amplitudes, and of less than 10 degrees for the phase (see last two rows of Tables 1 and 2). Only the phase of component P1 at mooring M2 presents a large difference (larger than 30 degrees) between the model and the measurements. This difference is probably due to the fact that the model grid size (about $9 \mathrm{~km}$ ) does not allow an accurate sampling of the bathymetry in the model. If the error remains weak in the Persian Gulf (mooring M1 lies at $25 \mathrm{~m}$ depth in reality and at $32 \mathrm{~m}$ in the model), this error is much larger at the exit of the Straits where the topographic gradients are large (mooring M2 lies at $113 \mathrm{~m}$ depth in reality and at $203 \mathrm{~m}$ in the model).

\section{Conclusions}

We have implemented a finite-difference code of a shallow-water model for a homogeneous ocean. This model was forced by 7 tidal components at its southern boundary. It reproduced well the tidal elevations and currents over the Persian Gulf and, more generally, over the larger domain (the Northwestern Indian Ocean). The amphidromic points and the type of tidal variation (diurnal, semi-diurnal, mixed) were correctly reproduced. The model results were validated with success using data from 42 tidal gauges, both in the Persian Gulf and in the Arabian Sea. This success can be attributed to an accu- 


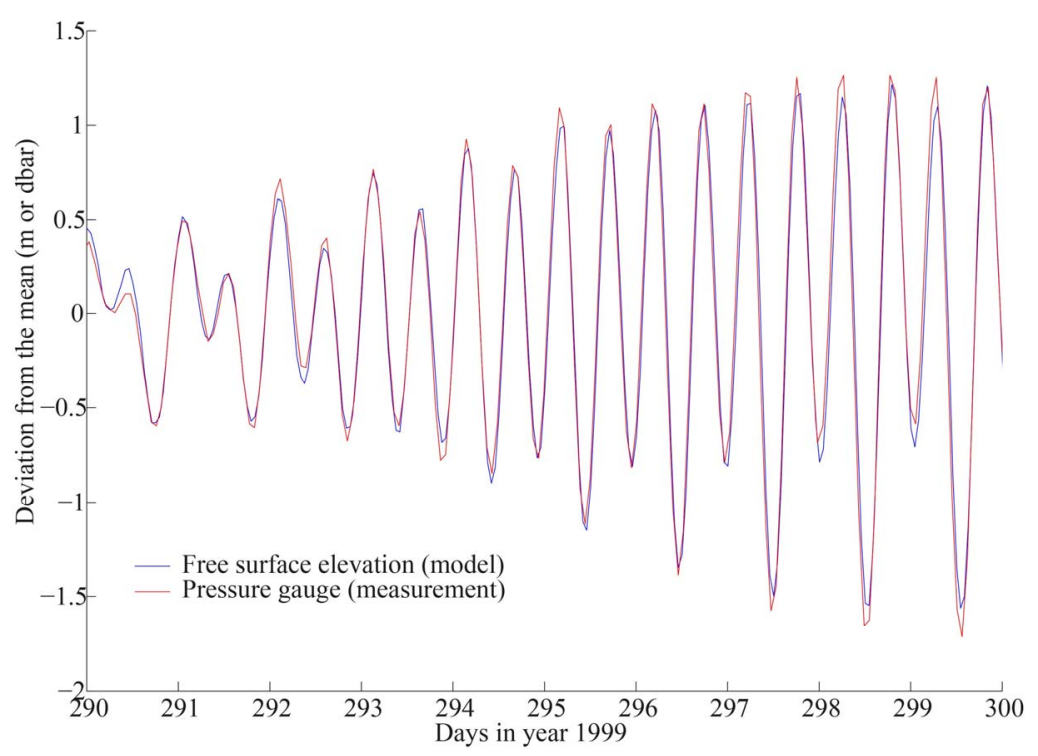

Figure 6. Measured pressure anomaly (in red, in dbars) and modeled free surface elevation (in blue, in meters) with respect to the day of year 1999.

rate bathymetry and to the simultaneous inclusion of the 7 tidal components, which can nonlinearly interact.

The tidal currents provided by the model are fast in the Straits of Hormuz (among other locations) and thus they will efficiently contribute to mix the outflowing Persian Gulf Water with the inflowing Indian Ocean Surface Water. They can also be fast in shallow areas and thus they will have an important effect on the hydrology in the whole Persian Gulf. But the Eulerian residual tidal currents are weak, and therefore they will be a priori negligible in the general circulation on the long term. Finally, the model accurately reproduced the measurements of free surface elevation and of tidal components at three moorings during the GOGP99 experiment.

This tidal model is now validated and can be included in a 3D primitive equation model for further studies. These studies will first address the effect of the wind on river plumes and later the regional circulation forced by the wind and by the atmospheric (heat and freshwater) fluxes.

\section{Acknowledgements}

The authors were funded by SHOM (French Navy Hydrographic and Oceanographic Service), by IFREMER (French Institute for Marine Research and Development), by the MNHN (Museum National d'Histoire Naturelle) and by UBO (Universite de Bretagne Occidentale). XC thanks DGA (Defence Research Agency) for support under REI program COMINO.

\section{REFERENCES}

[1] A. Defant, "Physical Oceanography," Pergamon Press,
Vol. 2, 1960.

[2] K. T. Bogdanov, "Propagation des Ondes de Marees et des Variations de Marees du Niveau du Golfe Persique,” Marees Terrestres, Vol. 101, 1988, pp. 7004-7009

[3] L. Von Trepka, "Investigations of the Tides in the Persian Gulf by Means of a Hydrodynamical Numerical Model,” Proceedings of the Symposium on Mathematical Hydrodynamical Investigations of the Physical Processes in the Sea, Institut fur Meereskunde der Universitat Hamburg, Vol. 10, 1968, pp. 59-63.

[4] D. J. Evans-Roberts, "Tides in the Persian Gulf," Consulting Engineer, Vol. 43, No. 6, 1979, pp. 46-48.

[5] R. W. Lardner, M. S. Belen and H. M. Cekirge, "Finite Difference Model for Tidal Flows in the Arabian Gulf," Computers \& Mathematics with Applications, Vol. 8, No. 6, 1982, 425-444.

[6] L. Kantha, “Tides-A Modern Perspective,” Marine Geodesy, Vol. 21, No. 4, 1998, pp. 275-297.

[7] R. Proctor, R. A. Flather and A. J. Elliott, "Modeling Tides and Surface Drift in the Arabian Gulf: Application to the Gulf Oil Spill," Continental Shelf Research, Vol. 14, No. 5, 1994, pp. 531-545.

[8] S. Pous, "Dynamique Oceanique dans les Golfes Persique et d'Oman”, Ph.D. Thesis, Universite de Bretagne Occidentale, Brest, 2005, 365 p.

[9] P. Lazure and F. Dumas, “An External-Internal Mode Coupling for a 3D Hydrodynamical Model for Applications at Regional Scale (MARS)," Advances in Water Resources, Vol. 31, No. 2, 2007, pp. 233-250. doi:10.1016/j.advwatres.2007.06.010

[10] P. Pontius, L. Kantha, V. Anantharaj and T. J. Bennett, "Tidal Modeling in Marginal and Semi-Enclosed Seas," Proceedings of the MTS 94 Conference, Challenges and Opportunities in the Marine Environment, Washington, 7-9 September 1994, pp. 770-776. 
[11] P. C. Roos and H. M. Schuttelaars, "Influence of Topography on Tide Propagation and Amplification in SemiEnclosed Basins,” Ocean Dynamics, Vol. 61, No. 1, 2011, pp. 21-38.

[12] V. C. John, "Harmonic Tidal Current Constituents of the Western Arabian Gulf from Moored Current Measurements," Coastal Engineering, Vol. 17, 1992, pp. 145-151. doi:10.1016/0378-3839(92)90016-N

[13] C. A. Blain, "Barotropic Tidal and Residual Circulation in the Arabian Gulf,” In: M. L. Spaulding and H. L. Butler Eds., Proceedings of the 5th International Conference on Estuarine and Coastal Modeling, American Society of
Civil Engineers, 1998, pp. 166-180.

[14] S. Pous, X. Carton and P. Lazure, "Hydrology and Circulation in the Straits of Hormuz and the Gulf of Oman; Results from the GOGP99 Experiment. I. Straits of Hormuz,” Journal of Geophysical Research, Vol. 109, No. C12037, 2004, pp. 1-15.

[15] S. Pous, X. Carton and P. Lazure, "Hydrology and Circulation in the Straits of Hormuz and the Gulf of Oman; Results from the GOGP99 Experiment. II. Gulf of Oman”, Journal of Geophysical Research, Vol. 109, No. C12038, 2004, pp.1-26. 